\section{Serum C3 levels in acute glomerulonephritis}

Sir,

The article entitled 'Serum C3 levels in acute glomerulonephritis and postnephritic children' by $M$. PopovićRolovic (Archives, 48, 622, 1973) was read with interest and, while accepting this paper as a valuable contribution to our knowledge of the subject, we would like to make several comments about the interpretations.

One of the difficulties in evaluating long-term data in patients with suspected poststreptococcal acute glomerulonephritis (AGN) is to establish irrefutably the diagnosis at onset. Using similar criteria for the clinical diagnosis of AGN, Travis et al. (1973) entered 60 children into a prospective study. On renal biopsy, however, $10 \%$ of the children were discovered to have histological findings other than those of AGN, i.e. exacerbation of chronic glomerulonephritis in 5 patients and focal glomerulonephritis in the other patient. In each incident the acute exacerbation of clinical nephritis occurred after a streptococcal infection. A similar incidence of previously undetected chronic renal disease has been noted in other studies (Edelmann, Greifer, and Barnett, 1964; Vernier et al., 1959). It is therefore apparent that clinical and laboratory criteria alone are often insufficient for documentation of AGN.

Without histological confirmation it is difficult to interpret the findings of this study: that a larger proportion of children than usual $(20 \%)$ have persistent hypocomplementaemia of up to 6 months' duration. Levels of C3 in AGN have recently been shown to return to normal in as short a time as 5 weeks (West, 1973). Hence, it is tempting to entertain the possibility that some of these children belong to one of the other types of hypocomplementaemic nephritis. In this context it is ferhaps not without significance to note that the average age of children in the authors's postnephritic, hypocomplementaemic group is 11.7 years, an age of onset that is unusually high for AGN and where a diagnosis of membranoproliferative glomerulonephritis should be considered. In lieu of renal histological confirmation this possibility could be investigated by measurement of serum complement profiles (West, 1973) in which levels of $\mathrm{C} 1, \mathrm{C} 4$, and $\mathrm{C} 2$ are found to be normal.

E. H. SMITH, L. B. TRAVIS, W. B. LORENTZ, JR., H. F. CARVAJAL, and M. BERGER

Division of Nephrology, University of Texas

Medical Branch,

Galveston, Texas 77550 ,

U.S.A.

\section{REFERENCES}

Edelmann, C. M., Jr., Greifer, I., and Barnett, H. L. (1964). The nature of kidney disease in children who fail to recover from apparent acute glomerulonephritis. fournal of. Pediatrics, 64, 879.

Travis, L. B., Dodge, W. F., Beathard, G. A., Spargo, B. H., Lorentz, W. B., Carvajal, H. F., and Berger, M. (1973). Acute glomerulonephritis in children. A review of the natural history with emphasis on prognosis. Clinical Nephrology, 1, 169.

Vernier, R. L., Worthen, H. G., Wannamaker, L. W., and Good, R. A. (1959). Renal biopsy studies of the acute exacerbation in glomerulonephritis. American fournal of Diseases of Children, 98, 653.

West, C. D. (1973). Hypocomplementemic glomerulonephritis. Kidney, 6, 1.

\section{Dr. Popović-Rolović comments as follows:}

I agree that it is sometimes difficult to ascertain the diagnosis of acute poststreptococcal glomerulonephritis (AGN) without renal biopsy. However, even if renal biopsy is done the diagnosis may still be uncertain without further clinical and laboratory data, since it has been shown that other types of postinfective glomerulonephritis may have similar histological, immunohistological, and ultrastructural features (Black, Challacombe, and Ockenden, 1965; Gutman et al., 1972; Stickler et al., 1968; Tu, Shearn, and Lee, 1969). This is why I would like to substantiate the diagnosis of AGN in my patients with some supplementary clinical and laboratory data.

Since other authors have also reported that C3 concentration may be reduced during the first 8 to 12 weeks (Derrick, Reeves, and Dillon, 1970; Cameron et al., 1973), I shall refer here only to 8 patients, the 4 of our series who had reduced values in the 4th month and the 4 with reduced values in the 5 th and 6th months (Tables I and II in the Archives article).

All these patients had symptoms typical of AGN at the onset of the disease, but their initial proteinuria never exceeded $1000 \mathrm{mg} / 24 \mathrm{hr}$. They all lost their oedema and the blood pressure returned to normal within 2 to 3 weeks. Haematuria disappeared in all within 6 to 24 weeks. In 6 patients proteinuria lasted from 6 to 16 weeks; in 1 patient proteinuria decreased to $133 \mathrm{mg} / 24 \mathrm{hr}$ in the 8th week and was intermittent during the next 3 years, never exceeding $147 \mathrm{mg} / 24 \mathrm{hr}$; and in 1 patient was $180 \mathrm{mg} / 24 \mathrm{hr}$ in the $8 \mathrm{th}$ week of the disease, $208 \mathrm{mg} / 24 \mathrm{hr}$ after 6 months, and normal after 1 year. All the patients are now (3 to 4 years since the onset of the disease) without clinical and laboratory symptoms and have normal urinary findings.

I think that the only other two types of glomerulonephritis, apart from AGN, in which a similar course of the disease can be found are idiopathic focal glomerulonephritis, and hypocomplementaemic 'silent' persistent nephritis (Northway et al., 1969). The former can easily be ruled out because the patients had hypo- 
complementaemia at the beginning of the disease, while in the latter case it seems most unlikely that there could be 8 cases with a 'silent' course of chronic hypocomplementaemic persistent nephritis in a single group of patients. Apart from this, reduction of $\mathrm{C} 3$ concentration found in patients within a period of 4 to 6 months was only slight or at the lower limits of normal values (Table). In some patients slight falls in concentration

\section{TABLE}

Sequential determination of serum C3 levels ( $\mathrm{mg} / 100$ $\mathrm{ml}$ ) in 8 patients with acute poststreptococcal glomerulonephritis

\begin{tabular}{|c|c|c|c|c|c|c|c|c|c|}
\hline \multirow{2}{*}{ Case no. } & \multicolumn{5}{|c|}{ Week } & \multicolumn{4}{|c|}{ Month } \\
\hline & 1 & 2 & $3-4$ & $5-6$ & $7-8$ & 3 & 4 & $5-6$ & $6-12$ \\
\hline $\begin{array}{l}1 \\
2 \\
3 \\
4 \\
5 \\
6 \\
7 \\
8\end{array}$ & $\begin{array}{c}8 \\
15 \\
8,8 \\
11\end{array}$ & $\begin{array}{r}10 \\
7 \\
31\end{array}$ & $\begin{array}{l}30 \\
35 \\
29 \\
33 \\
27 \\
53\end{array}$ & $\begin{array}{l}56 \\
72 \\
66\end{array}$ & $\begin{array}{l}70 \\
60 \\
59\end{array}$ & $\begin{array}{l}82 \\
67 \\
80\end{array}$ & $\begin{array}{c}62 \\
71 \\
69 \\
54\end{array}$ & $\begin{array}{l}82 \\
81 \\
68 \\
66 \\
70 \\
56\end{array}$ & 83 \\
\hline
\end{tabular}

Note: Cases 1 to 4 with reduced C3 levels in 4th month of the disease, Cases 5 to 8 in 5 th to 6 th month. Normal values (mean \pm 2 SD) $109 \cdot 5 \pm 32 \cdot 6 \mathrm{mg} / 100 \mathrm{ml}$.

occurred even after normal values were obtained. C3 concentration in patients with hypocomplementaemic chronic glomerulonephritis is usually markedly reduced. Similar findings in a previously biopsied group of patients with AGN were also found by Treser et al. (1969). 2 of their 23 patients had low C3 levels for 4 months, and another 2 showed transient depression in the 24th month after the onset of the disease.

The age of Case 8 (Table III) of my paper was misprinted as 15 years instead of 5 , so that the average age of the patients in the postnephritic hypocomplementaemic group was 9.6 at subsequent testing. It is interesting to note that the average age of these patients at the onset of the disease was $5 \cdot 8$ years.

MILANA POPOVIĆ-ROLOVIĆ
Beograd, Dečja Klinika, Tiršova 10, Yugoslavia.

\section{REFERENCES}

Black, J. A., Challacombe, D. N., and Ockenden, B. G. (1965). Nephrotic syndrome associated with bacteraemia after shunt operations for hydrocephalus. Lancet, 2, 921.

Cameron, J. S., Vick, R. M., Ogg, C. S., Seymour, W. M., Chantler, C., and Turner, D. R. (1973). Plasma C3 and C4 concentrations in management of glomerulonephritis. British Medical fournal, 3, 668.

Derrick, C. W., Reeves, M. S., and Dillon, H. C. (1970). Complement in overt and asymptomatic nephritis after skin infection. fournal of Clinical Investigation, 49, 1178.

Gutman, R. A., Striker, G. E., Gilliland, B. C., and Cutler, R. E. (1972). The immune complex glomerulonephritis of bacterial endocarditis. Medicine, 51, 1.

Northway, J. D., McAdams, A. J., Forristal, J., and West, C. D. (1969). A 'silent' phase of hypocomplementemic persistent nephritis detectable by reduced serum beta 1 c-globulin levels. fournal of Pediatrics, 74, 28.
Stickler, G. B., Shin, M. H., Burke, E. C., Holley, K. E., Miller, R. H., and Segar, W. E. (1968). Diffuse glomerulonephritis associated with infected ventriculoatrial shunt. New England fournal of Medicine, 279, 1077.

Treser, G., Ehrenreich, T., Ores, R., Sagel, I., Wasserman, E., and Lange, K. (1969). Natural history of apparently healed acute poststreptococcal glomerulonephritis in children. Pediatrics, 43, 1005.

Tu, W. H., Shearn, M. A., and Lee, J. C. (1969). Acute diffuse glomerulonephritis in acute staphylococcal endocarditis. Annals of Internal Medicine, 71, 335.

\section{Hyperglycaemia and uraemia in hyperosmolar dehydration}

Sir,

I read with interest the report by Heggarty, Trindade, and Bryan (Archives, 1973, 48, 740) concerning the hyperglycaemia which accompanies hypernatraemic dehydration. As was suggested by the authors, the metabolic acidosis may have contributed to the defective peripheral glucose utilization. However, we have shown (Nitzan and Zelmanovsky, 1968a) that hypernatraemia as such, of the degree encountered clinically, may have a diabetogenic effect. Rats rendered hypernatraemic by water deprivation and subcutaneous injections of hypertonic sodium solutions showed increased fasting blood glucose as well as a decreased ability to dispose of an exogenous glucose load, even in the presence of normal acid-base balance. Other contributory factors may be the severe uraemia shown by the dehydrated infants (O'Brien and Sharpe, 1965) and/or the intracellular potassium depletion which may be present in hypernatraemic states (Spergel et al., 1967; Finberg, 1957). Hyperosmolarity has been reported to stimulate glucose uptake and ${ }^{14} \mathrm{C}$ incorporation from ${ }^{14} \mathrm{C}$-labelled glucose into $\mathrm{CO}_{2}$ in rat adipose tissue and diaphragm in vitro (Kuzuya, Samols, and Williams, 1965). In view of this observation, the possibility that the hypernatraemic glucose intolerance which was found in vivo might be causally related to a disturbed secretion of the hormones which regulate carbohydrate metabolism should also be considered. Since hypernatraemia may cause injury to the central nervous system (Finberg, 1959), further studies will be necessary to determine whether lesions of the hypothalamus play a role in the production of the glucose intolerance (Schoolman, Dubin, and Hoffman, 1955).

Uraemia invariably occurs in clinical syndromes associated with hypernatraemia (Schoolman et al., 1955). The raising of urea levels can be explained by underperfusion of the kidneys due to the dehydration which often accompanies hypernatraemic states. In addition, severe degrees of hypernatraemia, even without circulatory disturbances, can induce definite histological damage in the renal tissue (Rush et al., 1961). We have shown (Nitzan and Zelmanovsky, 1968b) that hypernatraemia exerts a catabolic effect leading to enhanced production of urea as the principal end product of protein metabolism. This excessive tissue catabolism may have contributed to the severity of the uraemia in the cases 